\title{
Research of Crystallization of Aluminums Cast Iron
}

\author{
Saule Kaldybayeva
}

Kazakh National Technical University named after K.I. Satpayev, Department of Materials Engineering, 050013 Almaty, Satpayev st.22, Republic of Kazakhstan,

*Corresponding Author: sayle_78_78@mail.ru

\begin{abstract}
In work was researched the composition and structure of high-alloyed aluminum cast iron ЧЮ22Ш. Crystalization of cast iron ЧЮ22Ш (ЧЮ22Ш standard cast iron) was researched by phase transformation, leaking upon its harden and cooling -down. High-alloyed materials are widely applied as the heat-resistant materials. Overall content of that reaches $30-50 \%$ and more. Previous performed researches allowed to optimize the content high-alloyed aluminum cast iron ЧЮ22Ш, to research its structure, casting and operational characteristics, to develop technological mode of melting, casting and thermal / heat treatment casts, to held its industrial examination and to determine perspective direction of its application. However, in present time ability of the aluminum cast iron ЧЮ22W is being used not sufficiently.
\end{abstract}

Keywords: heavily doped aluminum cast iron structure, the composition of the phases, thermal properties, specific heat, thermal conductivity, thermal diffusivity

\section{INTRODUCTION}

Development of heat power engineering, as well as other sectors of the industry moved by the direction on identification of working modes of the equipments. Under such conditions all working parameters of the speed, pressure and temperature increases. For procurement of the stable work of equipment in such condition materials with high quality is required. Specifically, for work in conditions of high temperature the heatproof and heat-resistant materials are applied. In not high mechanical load the useful life of the equipment is defined by heat-resistance, i.e resistance in high- temperature of gaseous corrosion in atmosphere. Gaseous environment in industrial aggregates has widen spectrum of compositions starting from simple air environment and finishing by the high corrosive activity of the environment, for example, environment with high concentration sulfurs and vanadium that contains gases.

High-alloyed materials have been widely applied as the heat-resistant materials. Overall content of that reaches $30-50 \%$ and more. Therefore, the cost of heat-resistant alloys is very high. 
Nevertheless, the useful life of the working areas with heat-resistant alloys is low. It stipulates increasing costs for supporting in working conditions of the aggregates with high working temperature, as the example, fire bars of sintering machines, spare areas of the boiler installments, kilning, heating and glass-worked kilns, crucibles for melting fusible metals and shapes for cast.

Previous performed researches (1-4) allowed to optimize the content of high-alloyed aluminum cast iron ЧЮ22Ш, to research its structure, casting and operational characteristics, to develop technological mode of melting, casting and thermal / heat treatment casts, to held its industrial examination and to determine perspective direction of its application. However, in present time ability of the aluminum cast iron ЧЮ22Ш is being used not sufficiently. One of the constraints is not sufficient research patterns of its crystallization, and also absence of the data about thermal physic characteristics, which don't allow correctly use modern methods of induced casting processes for improvement of technologies in manufacturing of the casts. This work is devoted for research of those questions.

\section{EXPERIMENTAL WORK}

\subsection{Crystallization and Structure of Iron}

The crystallization of the cast iron ЧЮ22Ш researched by phase transformation, leaking upon its hardening and cooling -down. Due to absence of the diagram of the condition Fe-C-Al and FeC-Si-Al used computer program Thermo-Calc with the help of which built polythermal crosssection for triple and fourfold system Fe-C-Al and Fe-C-Si-Al. Upon this they variated by the content of the carbon within the range of $1,5-2,5 \%$, silicon $-1-2 \%$ and aluminium $-15-35 \%$.

Obtained results shows that crystalization of the cast iron, the content of which is equivalent to ЧЮ22Ш 2 and comprising 2 \% C, 1 \% Si and $22.5 \% \mathrm{Al}$, begins (Figure 1) with separation from liquid cast iron initial crystals of the graphite. Then crystalization of double eutectic takes place, that contains from solid solution on the base of alloyed aliminium of the ferrite $(\alpha-$ phases) and graphite. Then from the remains of the liquid phase separated more alloyed aluminium of the ferrite. Upon subsequent cooling of the cast iron as the result of decrease of the aluminium solubility in $\alpha$ - phase from it separated carbide $\mathrm{Al}_{4} \mathrm{C}_{3}$.

Those data conforms with the results of thermographic research. Figure 2 shows experimentally received curve of cooling of cast iron ЧЮ22Ш.

\subsection{Research of Structure of Cast Iron ЧЮ22Ш}

Cooling curve, uppermost, indicated that cast iron mainly crysltalizes with constant temperature, but endures insignificant pre-euthethic and post-euthetic crystalization. On temperature curve the cooling -down areas of the liquid cast iron can be separated 1, preeuthethic crystalization of the initial graphite 2, euthethic crystalization 3, post-euthethic crystalization of the ferrite ( $\alpha$ - phase) 4, cooling down of the solid cast iron 5 and separation from oversaturated solid solution ( $\alpha$ - phase) aluminium that contains carbide phase 6 . 
Presence of the euthethic crystalization was known before, and according to data (1) it flows in cast iron with temperature of $1230-1280{ }^{\circ} \mathrm{C}$.

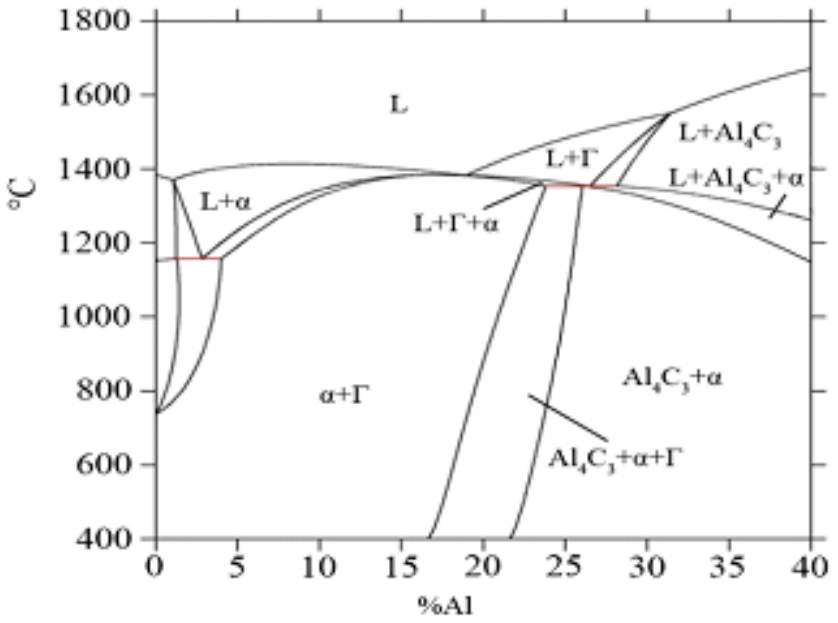

Fig. 1. Polythermal cross-section of phase diagrams of condition system $\mathrm{Fe}-(2 \% \mathrm{C})-\mathrm{Al}$ (a) and $\mathrm{Fe}-(2 \% \mathrm{C})-(1 \% \mathrm{Si})-\mathrm{Al}(6)$

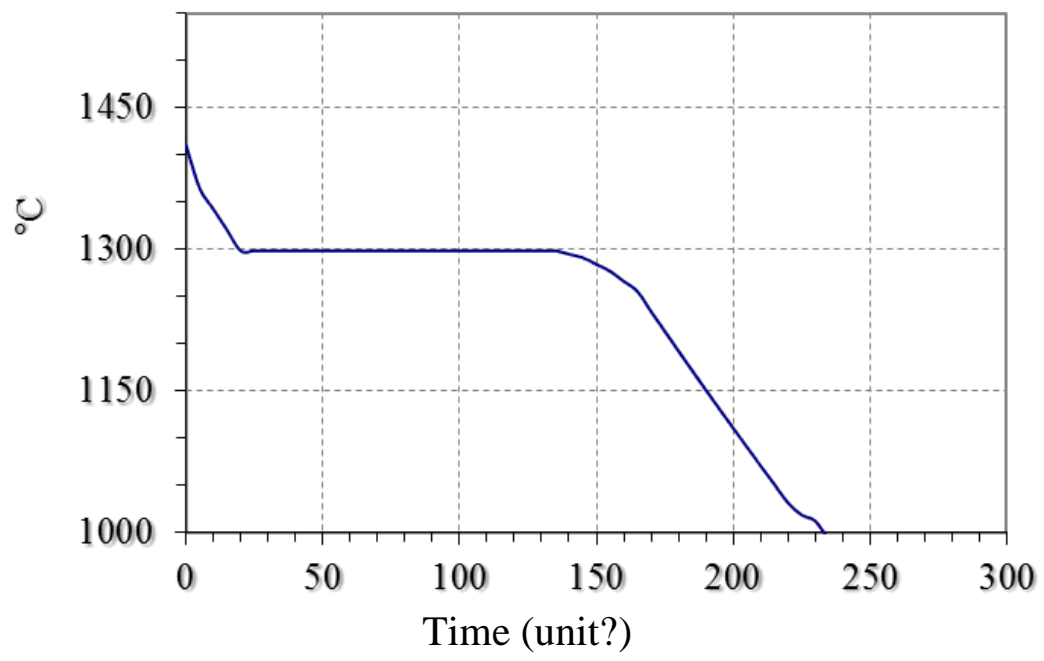

Fig. 2. Cooling of the cast iron curves.

Newness of the obtained results that euthethic crystalization can flow with higher temperature (15-60 ${ }^{\circ} \mathrm{C}$ ). In addition, identified the presence of the pre-euthethic and post-euthethic crystalization, also phase transformation in solid condition with separation from solid solution of the aluminum in iron ( $\alpha$ - phase) iron-aluminium carbide of the type $\mathrm{Fe}_{3} \mathrm{AlC}_{\mathrm{x}}$ ( $\varepsilon$ - phase).

Also obtained results clarified to which phases in which order, in which combination and with which temperature separated upon changing from high-alloyed aluminium cast iron in liquid condition to solid. 
Big length of the horizontal area on cooling curve (see Figure 2) confirms about development of the euthethic crystalization and formation in casts with conformed structure. According to cooling curves and polythermal cross-sections, in cast iron ЧЮ22Ш must be present three ingredients: inclusions of the initial graphites (I), graphite-ferrite euthethic (II) and secondary carbide $\mathrm{Al}_{4} \mathrm{C}_{3}$ (III), that is separated after euthethic crystalization. However, the real structure is different from described.

Compositions of phases were additionally researched on electronic microscope with microanalyzer. Obtained results, presented in Picture 4, confirms that matrix a-ferrite, alloyed with aluminium till 23\% ( $\alpha$ - phase), as for dark inclusions with round shaped c-graphite. Data by stitch inclusions b confirms that they contains iron, aluminium and carbon and therefore can be considered as the iron aluminium carbides. However, atomic shares of the iron in it, according to repeated definitions, only in 1.3-1.6 times exceeding the atomic share of the aluminium. Therefore, it is considered as the iron aliminium carbides of variable compositions of the type $\mathrm{Fe}_{1,5} \mathrm{AlC}_{\mathrm{x}}$.

Fig. 3 shows a typical microstructure of cast iron. In netravlenom distinguished black graphite nodules were uniformly distributed in the metal matrix. In the matrix itself, there are different light phases, and stitches of dark color inclusions. In the etched form of graphite inclusions are located on a white background in the center enclosed by the "dark fence" areas. With the large increase in "dark fence" is revealed as the row-inclusion of bizarre shapes.
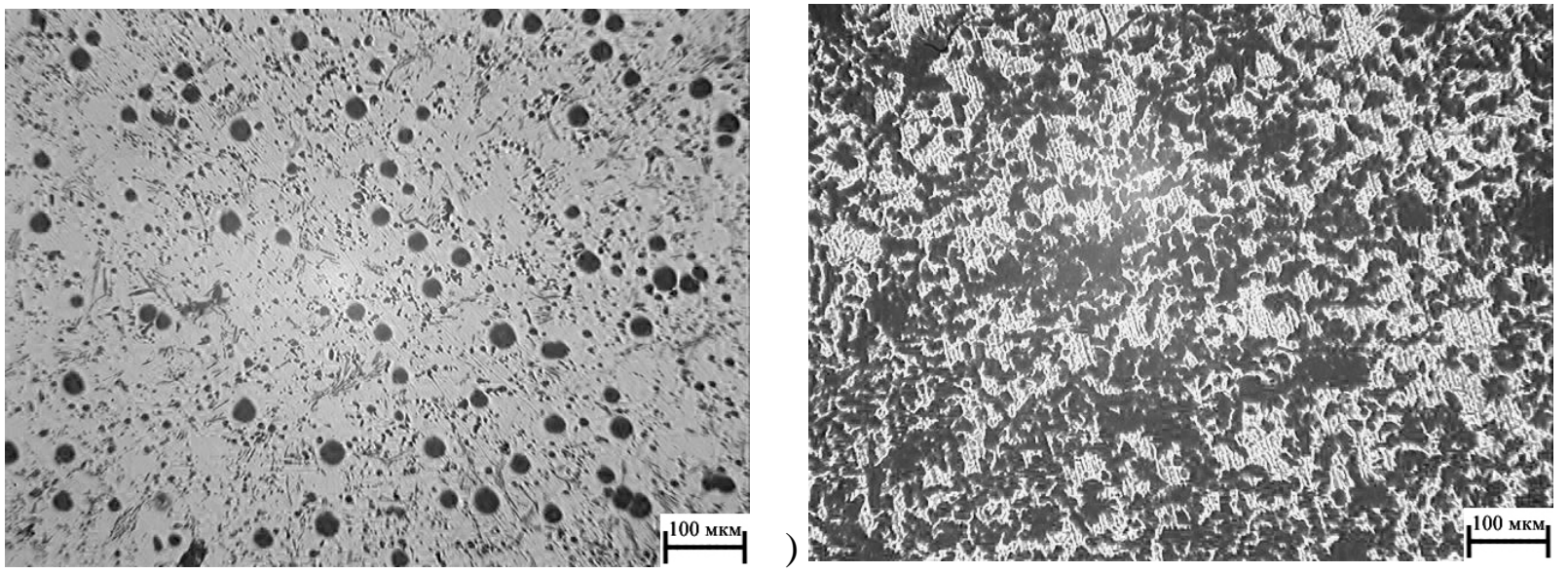

Fig. 3. Structure of iron ЧЮ22Ш before (a) and after etching (b)

Light and dark phases previously identified by measuring their microhardness and compare these values with published data. Microhardness of the light phase is equal to $413 \mathrm{HV}$, which corresponds to the microhardness of the doped aluminum ferrite ( $\alpha$ - phase). A dark crystalline phase has a microhardness of $650 \mathrm{HV}$, so it was identified as iron - aluminum carbide Fe3AlCx ( $\varepsilon$ - phase), microhardness, which is in the range $640-850 \mathrm{HV}$.

Compositions of phases were further studied under an electron microscope with a microanalyzer. The results obtained are shown in Fig. 4, confirm that the matrix a ferrite, aluminum-doped to $23 \%$ ( $\alpha$ - phase), and dark inclusions of round shape with - 
graphite. Data on the row-inclusion b indicate that they contain iron, aluminum and carbon, and therefore can be regarded as iron-aluminium carbides. However, the atomic fraction of iron in them, according to multiple definitions, is 1.3-1.6 times higher than the atomic fraction of aluminum. Therefore, they are most likely to be iron-aluminium carbide of variable composition such as Fe1.5AlC .

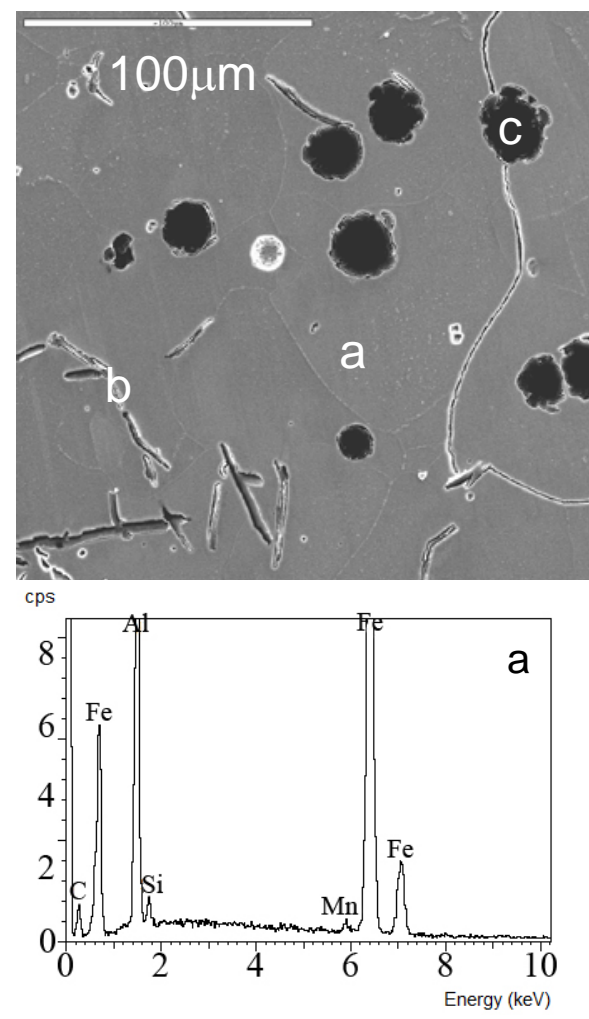

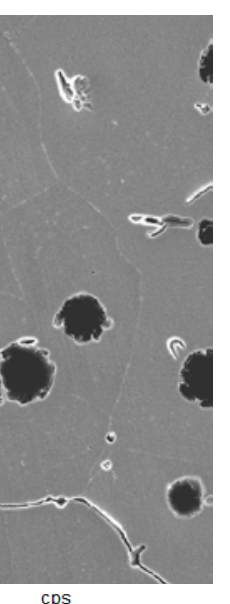

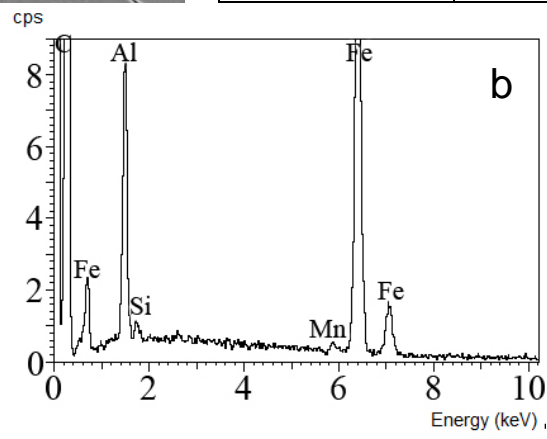

\begin{tabular}{|c|r|r|r|r|}
\hline \multirow{2}{*}{ Element } & \multicolumn{2}{|c|}{ in wt\% } & \multicolumn{2}{c|}{ in at\% } \\
\cline { 2 - 5 } & \multicolumn{1}{c|}{$\mathrm{A}$} & \multicolumn{1}{c|}{$\mathrm{b}$} & \multicolumn{1}{c|}{$\mathrm{a}$} & \multicolumn{1}{c|}{$\mathrm{b}$} \\
\hline $\mathrm{Al}$ & 22,99 & 21,53 & 37,79 & 35,84 \\
\hline $\mathrm{Si}$ & 1,33 & 1,29 & 2,11 & 2,07 \\
\hline $\mathrm{Mn}$ & 0,88 & 1,51 & 0,71 & 1,23 \\
\hline $\mathrm{Fe}$ & 74,79 & 75,67 & 59,39 & 60,86 \\
\hline Total & 100,00 & 100,00 & 100,00 & 100,00 \\
\hline
\end{tabular}

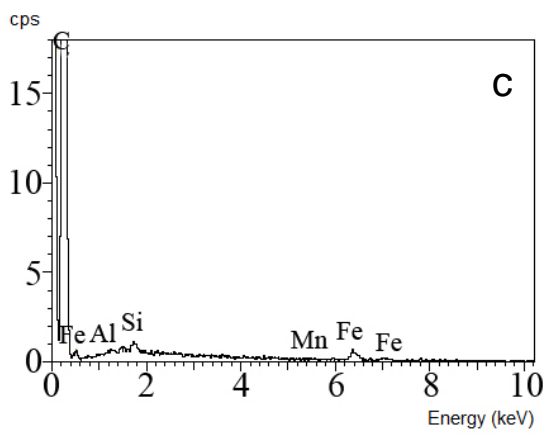

Fig. 4. Results of the micro X-ray spectrometry analysis of the phases in cast iron ЧЮ22Ш.

Actual structure of the cast iron is different from supposed by several indications. Uppermost, it is not possible to explicitly detect separations of the initial graphite. In addition, in cast iron, instead of expected carbide $\mathrm{Al}_{4} \mathrm{C}_{3}$, iron-aliminium carbide $\mathrm{Fe}_{1,5} \mathrm{AlC}_{\mathrm{x}}$ is formed.

Perhaps under conditions of high undercooling is thermodynamically favorable to form instead of a double carbide $\mathrm{Al}_{4} \mathrm{C}_{3}$ triple carbide, and not even $\mathrm{Fe}_{3} \mathrm{AlC}_{\mathrm{x}}\left(\varepsilon\right.$ - phase), and $\mathrm{Fe}_{1.5} \mathrm{AlC}_{\mathrm{x}}$.

Thermophysical properties of iron are needed for computer simulation of melt filling the mold cavity, the solidification and cooling of castings in them in order to select the best technology option of obtaining them without casting defects. However, such information on iron ЧЮ22Ш are absent.

In this work was measured heat capicity, thermal conductivity and thermal diffusivity of iron ЧЮ22Ш in the temperature range $500-1000{ }^{\circ} \mathrm{C}$. Experiments were conducted in the laboratory of the Korean Institute for Materials Science (KIMS) on the instrument NETZSCH LFA 457 Micro-Flash $^{\circledR}$. The tests were conducted on samples made of strong cast samples. Sample sizes 
were: diameter - $12.700 \mathrm{~mm}$, thickness - $3.1580 \mathrm{~mm}$. The density of iron was equal to 5909 $\mathrm{kg} / \mathrm{m}^{3}$.

\section{RESULT \& DISCUSSION}

\subsection{Thermophysical Properties of Cast Iron}

The results are shown in Table - 2 as the average of five measurements. In this case, the specific heat is measured with equal accuracy throughout the temperature range $- \pm 0,001 \mathrm{~J} /(\mathrm{kg} \cdot \mathrm{K})$. A thermal conductivity and thermal diffusivity were measured with varying precision: at low temperatures - $\pm 0,028 \mathrm{~W} /(\mathrm{m} \cdot \mathrm{K})$ and $\pm 0,009 \cdot 10-6 \mathrm{~m}^{2} / \mathrm{s}$ at elevated temperatures $- \pm 0,157 \mathrm{~W}$ / $(\mathrm{m} \cdot \mathrm{K})$ and $\pm 0,047 \cdot 10^{-6} \mathrm{~m} 2 / \mathrm{s}$, respectively.

Table 2. Thermophysical properties of cast iron ЧЮ22Ш

\begin{tabular}{|c|c|c|c|c|c|c|c|}
\hline \multirow[b]{2}{*}{ № } & \multirow{2}{*}{$\begin{array}{l}\text { Dimension of the } \\
\text { characteristics }\end{array}$} & \multicolumn{6}{|c|}{ Temperature, ${ }^{\circ} \mathrm{C}$} \\
\hline & & 500 & 600 & 700 & 800 & 900 & 1000 \\
\hline 1 & $\begin{array}{l}\text { Specific heat capacity } \mathrm{C}_{\mathrm{h}} \text {, } \\
\mathrm{Dj} /(\mathrm{kg} \cdot \mathrm{K})\end{array}$ & 536 & 549 & 559 & 565 & 573 & 585 \\
\hline 2 & $\begin{array}{l}\text { Heat-transfer capacity, } \lambda_{\mathrm{h}} \text {, } \\
\mathrm{Wt} /(\mathrm{m} \cdot \mathrm{K})\end{array}$ & 12,64 & 13,11 & 13,64 & 14,19 & 14,93 & 15,53 \\
\hline 3 & $\begin{array}{l}\text { Thermal diffusivity } a_{\mathrm{h}} \text {, } \\
10^{6} \mathrm{~m}^{2} / \mathrm{c}\end{array}$ & 3,99 & 4,04 & 4,13 & 4,25 & 4,41 & 4,49 \\
\hline
\end{tabular}

According to Table 2, heat capacity of iron ЧЮ22Ш with increasing temperature from 500 to $1000{ }^{\circ} \mathrm{C}$ increases from 536 to $585 \mathrm{~J} /(\mathrm{kg} \cdot \mathrm{K})$. Do not alloyed nodular cast iron within the range of $20-1000{ }^{\circ} \mathrm{C}$ the specific heat is $586-628 \mathrm{~J} /(\mathrm{kg} \cdot \mathrm{K})$ [2]. That is, these cast irons are comparable to the specific heat.

The thermal diffusivity of cast iron with increasing temperature is more important than heat from 12.64 at $500{ }^{\circ} \mathrm{C}$ to $15.53 \mathrm{~W} /(\mathrm{m} \cdot \mathrm{K})$ at $1000{ }^{\circ} \mathrm{C}$. Obtained values are much smaller than the values cited in the literature: $16.28 \mathrm{~W} /(\mathrm{m} \cdot \mathrm{K})$ at $200{ }^{\circ} \mathrm{C}$ and $26.75 \mathrm{~W} /(\mathrm{m} \cdot \mathrm{K})$ at $500{ }^{\circ} \mathrm{C}$. At the same temperature values differ by more than 2 times. It seems that the results obtained in the data are more reliable, since they were received by using more modern equipment, each value was measured five times and holds a wide temperature range. On this basis, we can assume that the aluminum cast ЧЮ22Ш has a thermal conductivity about 3 times lower than the unalloyed cast iron with ferritic matrix metal, which at $400^{\circ} \mathrm{C}$ has a thermal conductivity $38 \mathrm{~W} /(\mathrm{m} \cdot \mathrm{K})$ [2]. Because the thermal diffusivity of unalloyed cast iron decreases with increasing temperature, while the iron ЧЮ22Ш on the contrary, increases in the area of operating temperature of 1000 $1100{ }^{\circ} \mathrm{C}$, this difference should be heavily reduced.

Diffusivity coefficient of iron ЧЮ22Ш increases monotonically with $4 \cdot 10^{-6} \mathrm{~m}^{2} / \mathrm{s}$ to $4,5 \cdot 10-6$ $\mathrm{m}^{2} / \mathrm{s}$ with increasing temperature from 500 to $1000{ }^{\circ} \mathrm{C}$. The absence of data doesn't allow to compare these values. The not alloyed nodular cast iron (NCI) is equal to $(5,5-6,5) \cdot 10-6 \mathrm{~m}^{2} / \mathrm{s}$ at $600{ }^{\circ} \mathrm{C}$ and $(5,0-5,6) \cdot 10-6 \mathrm{~m}^{2} / \mathrm{s}$ at $800{ }^{\circ} \mathrm{C}$ [2]. Comparison of the data shows that the iron 
ЧЮ22Ш at 600 and $800^{\circ} \mathrm{C}$ has a thermal diffusivity at 33 and $20 \%$ lower, respectively, but at higher temperatures the thermal irons ЧЮ22Ш and NCI will be a little different.

\section{CONCLUSIONS}

1. The researches performed significantly enrich our knowledge of the sequence, nature and temperatures of phase transformations occurring during solidification of cast iron.

2. Shown that the actual structure of iron is different from the predictable and this is probably due to the no equilibrium conditions of crystallization in the mold.

3. First determined the specific heat, thermal conductivity and thermal diffusivity in the temperature range $500-1000{ }^{\circ} \mathrm{C}$.

4. Using the results of the study will more adequately address the technological issues of producing high-quality cast iron ЧЮ22Ш.

\section{REFERENCES}

1. Alexandrov N.N., N.I. Klochnev. Production technology and properties of heat-resistant cast iron. M.: Engineering, 1964. - 174p.

2. Kovalevich E.V. Aluminum Cast Iron / Cast Iron: A Handbook. Ed. AD Sherman and A.A. Zhukov. Moscow: Metallurgy. 1991.-576. (S.447-479). 3. Bobro G. alloy cast iron. -M.: Metallurgy, 1976. - 288.

4. Kosnikov G.A., Morozova L.M. Aluminum construction for lightweight cast iron castings responsible destination / Foundry. - 1997. - № 5. - P.19-29.

5. Handbook of cast iron casting, Ed. NG Girshovich. L.: Engineering. 1978. - 758 p.

6. Foundry. Ed. I.B Kumanin. M., "Engineering”, 1971, 320 b.

7. Test of materials. Reference Blyumenauer H., H. Vorh, I. Hartz et al, Ed. H. Blyumenauera, trans. with him. - M.: Metallurgy, 1979, 448p.

8. General technical handbook / EA Walkers, VP Scribes, AB Paknis, etc. Under the general. Ed. EA Skorokhodova - 3rd ed. Revised. and add. - Moscow: Engineering,1989.-512. 